\title{
Development and Analysis of Blended Pineapple-Watermelon Ready To Drink (RTD) Juice.
}

\author{
G.O. Oyeleke', A. Ojo ${ }^{2}$, F.D. $\mathrm{Ajao}^{2}$ and R.O. Adetoro ${ }^{3}$ \\ ${ }^{1}$ Science Laboratory Technology Department, Osun State Polytechnic, Iree, Nigeria. \\ ${ }^{2}$ Food Science and Technology Department, Osun State Polytechnic, Iree, Nigeria. \\ ${ }^{3}$ Chemistry Department, Osun State College of Education, Ila- Orangun, Nigeria.
}

\begin{abstract}
The physicochemical properties of juice from pineapple and watermelon and their ready to drink (RTD) blends were carried out. The \% watermelon juice and pineapple juice of each formulation $(v / v)$ were BL1 (70:30), BL2 (60:40), BL3 (50:50), BL4 (30:70) and BL5 (40:60). The standards were done without blending the two juices SPJ (100\% standard pineapple juice) and SWJ (100\% standard watermelon juice). The results of the analysis of Vitamin C content (mg/g) gave 125.26 in SWJ, 38.90 in SPJ, 111.58 in BL1, 98.94 BL2, 86.31 $B L 3,72.63$ BLA and 84.21 BL5 respectively. The vitamin $C$ content of the RTD blends increase with high proportion of SWJ. The results revealed that all the blends especially 70:30 (watermelon: pineapple) gave an improved composition in terms of the physicochemical properties determined.
\end{abstract}

Keywords: Physicochemical, blends, ready to drink, pineapple, watermelon, juice, vitamin C

\section{Introduction}

Fruit juices are liquid, non-alcoholic products with a different degree of clarity and viscosity, obtained through pressing or breaking up the fruits with or without sugar or carbon dioxide addition [1]. Fruit juices are ready and rich sources of vitamins, fibre and mineral salts for human consumption [1]. Fruits consumption is beneficial to health and contributes to the prevention of degenerative processes, particularly in lowering the incidence and mortality rate of cancer and cardiovascular diseases [2]. Based on fruits antioxidant capacities, these fruit juices are used as indicators for healthy nourishment as well as protection factors of the human body against oxidative destruction [1].

The increasing social and economic importance of food products besides the technology complexity of producing, processing and fragile food materials requires a more extensive knowledge of their physical properties because the rheological properties play an important role in the handling and quality attributes of processed foods [3].

Present dietary scenario necessitates exploring the possibilities of incorporating novel ingredients in commonly consumed foods rather than developing new food product [4].

Food constitutes one of the most important foods for man. Their regular and copiously consumption maintains health and makes up for the losses in the human diet.

Costescu et al., [1] recommended the consumption of natural juices with pulp from food and medical points of view.

Pineapple (Ananas comusus) and watermelon (Citrullus lamatus) are considered for this purpose. The two fruits are always available all the year round in the markets throughout Nigeria especially in South-western part of the country.

Pineapple (Ananas comusus) belongs to the family of bromeliaceae. It is a tropical, perennial, drought tolerant plant that grows up to 5-8ft in height and spreads around about three to four feet. It is essentially a short stout stem with a rosette of waxy long, needle-tipped leaves. The fruit is described as compound (multiple) fruit that develops from many small fruits fused together around the central core. It pulp is juicy and fleshy with the stem serving as a supporting fibrous core. It is an excellent source of antioxidant vitamin $\mathrm{C}$ which is required for the collagen synthesis in the body.

Watermelon (Citrullus lanatus) belongs to the family Cucurbitaceae. This tropical flowering plant produces a special type of fruit with a thick rind (exocarp) and fleshy center (mesocarp and endocarp). Fresh watermelon may be eaten in a variety of ways and is often used to flavor drinks. Watermelon contains about $6 \%$ sugar by weight with the rest being mostly water. As with many other fruits like orange, grapes and lemons dominate the market and because of high demand for juicy materials to quench thirst as well as to improve health, there is need to examine other available fruits and possibly their blends (with other fruits) in order to satisfy the consumers need. The aim of this research is therefore to develop and determine chemical characteristics of ready to drink (RTD) fruit juices from pineapple and watermelon fruits. 
2.1 Materials

\section{Materials and Methods}

\subsection{Raw Sample Collection}

Pineapple and watermelon fruits used for the preparation of the juices and their blends were obtained from a local seller in Ayetoro market, Osogbo, Osun state, Nigeria. They were brought into the applied Chemistry laboratories of Osun state Polytechnic, Iree in a polythene bag and were identified as pineapple (Ananas comusus) and watermelon (Citrullus lanatus) by a botanist.

\subsection{Extraction of Juice}

The fruits were washed thoroughly in running water. Fruits were peeled with the help of stainless steel laboratory knife and seeds from watermelon were removed manually. The pulps were grinded separately and the juice extracted using a laboratory electric juice extractor. The extracted juice were filtered through double muslin cloth and immediately stored at refrigerated temperature further use.

\subsection{Blended Ready-To-Drink (RTD) Juice Preparation}

\section{Methodology}

Two standards (100\% pineapple and $100 \%$ watermelon) and five samples of blended ready to drink juice containing different percentages of pineapple and watermelon juice were developed.

Table: Physicochemical Characteristics of the Fruit Juices and their RTD Blends

\begin{tabular}{|l|l|l|l|l|l|l|l|}
\hline Parameters & SWJ & SPJ & BL1 & BL2 & BL3 & BL4 & BL5 \\
\hline Ash content (\%) & 0.62 & 0.44 & 0.54 & 0.49 & 0.46 & 0.53 & 0.52 \\
\hline Water content (\%) & 92.50 & 83.55 & 87.45 & 91.70 & 88.82 & 86.64 & 85.47 \\
\hline Organic matter (\%) & 93.38 & 99.56 & 99.46 & 99.51 & 99.54 & 99.47 & 99.48 \\
\hline Total solid $\left({ }^{\circ}\right.$ Brix) & 4.02 & 10.62 & 6.03 & 7.03 & 7.30 & 9.03 & 8.02 \\
\hline pH & 5.20 & 3.80 & 4.40 & 4.20 & 4.10 & 4.00 & 4.10 \\
\hline Specific gravity & 1.016 & 1.040 & 1.024 & 1.028 & 1.032 & 1.036 & 1.032 \\
\hline Refractive index at 20 ${ }^{0} \mathrm{C}$ & 1.337 & 1.349 & 1.342 & 1.343 & 1.344 & 1.346 & 1.345 \\
\hline Temperature ( $\left.{ }^{\circ} \mathrm{C}\right)$ & 25.00 & 26.00 & 26.00 & 26.00 & 26.00 & 26.00 & 26.00 \\
\hline Conductivity (umhos) & $2.9 \times 10^{3}$ & $3.4 \times 10^{3}$ & $3.1 \times 10^{3}$ & $4.0 \times 10^{3}$ & $3.8 \times 10^{3}$ & $3.65 \times 10^{3}$ & $3.96 \times 10^{3}$ \\
\hline Viscosity (Pal/Sec) & 1.15 & 1.30 & 1.21 & 1.25 & 1.46 & 1.31 & 1.23 \\
\hline Total sugar (\%) & 4.25 & 10.60 & 6.50 & 7.00 & 7.25 & 9.00 & 8.00 \\
\hline Sucrose (\%) & 4.00 & 10.00 & 6.00 & 7.00 & 8.00 & 9.00 & 8.00 \\
\hline Carbohydrate (\%) & 40.00 & 95.00 & 60.00 & 70.00 & 76.00 & 89.00 & 88.00 \\
\hline Titratable acidity (mg/g) & 30.00 & 124.00 & 51.00 & 63.00 & 77.00 & 89.00 & 82.00 \\
\hline Ascorbic acid (mg/g) & 125.26 & 38.95 & 111.58 & 98.94 & 86.31 & 72.63 & 84.21 \\
\hline Volatile acidity (mg/g) & 0.02 & 0.07 & 0.03 & 0.05 & 0.05 & 0.05 & 0.05 \\
\hline
\end{tabular}

Note

SWJ- $100 \%$ standard watermelon juice

BL1- $70 \%$ watermelon and $30 \%$ pineapple

BL3 - 50\% watermelon and 50\% pineapple

BL5 - $40 \%$ watermelon and $60 \%$ pineapple.

SPJ- $100 \%$ standard pineapple juice

BL2- $60 \%$ watermelon and $40 \%$ pineapple

BL4 - 30\% watermelon and $70 \%$ pineapple

\section{Discussion}

The physicochemical properties of the two standard fruit juices from pineapple and watermelon and their blends were presented on the table above.

Vitamin C contents of the standard watermelon juice of $125.26 \pm 0.05 \mathrm{mg} / \mathrm{g}$ was about three times more than that of standard pineapple juice of $38.95 \mathrm{mg} / \mathrm{g}$. The addition of pineapple juice to watermelon juice reduced the vitamin $\mathrm{C}$ contents while addition of watermelon juice to the pineapple juice increased the vitamin $\mathrm{C}$ contents of the blends. The developed ready to drink (RTD) fruit juices and SWJ were higher than the $60 \mathrm{mg} / \mathrm{day}$ recommended daily allowance of vitamin $\mathrm{C}$ needed by an adult male [5]. The vitamin $\mathrm{C}$ contents of the two standards and their blends are lower than the vitamin $\mathrm{C}$ content of blended cashew apple juice with some tropical juice [5].

The carbohydrate content $(\%)$ of the SPJ of $95.00 \pm 0.01$ was higher than $40.00 \pm 0.05$ of SWJ. The carbohydrate contents of the blends also showed some levels of improvement in BL1, BL2 and BL3 on addition of more pineapple juice to the blend. 
All the samples have higher $\mathrm{pH}$ values than $\mathrm{pH} 4.0$ reported for cashew/pineapple blend of ratio (4:1). SPJ with $\mathrm{pH}$ of 3.8 correspond to the $\mathrm{pH}$ value obtained for cashew/grape blend of ratio 20:1 [5]. The $\mathrm{pH}$ values were however similar to those reported for papaya and aloe vera juice [6]. The results on $\mathrm{pH}$ showed that standard pineapple juice is acidic and that of watermelon was of medium acidic medium.

Titrable acidity in $\mathrm{mg} / \mathrm{g}$ increases as the addition of pineapple juice to the watermelon increases. This increase in titrable acidity of the blends corresponds to decrease in $\mathrm{pH}$ as shown on the table above.

The total soluble solids (TSS) in Brix and total sugar (\%) were also found to increase with increase in the volume of pineapple added to the watermelon juice. Increase in TSS is an indication that the pineapple addition has resulted in high sugar-to-acid ratio in the blends and this confirmed a high correlation between total soluble solids and sugar content as observed by Ravi et al., [7]. The values obtained for the total solids were very much lower than the average of $11.7^{0}$ Brix reported for choke cherry fruit cultivars [8] and $16.7 \%$ TSS reported for pomegranate fruit juice by [10]. The increase in TSS on addition of pineapple to watermelon could also be attributed to the conversion of polysaccharides and other constituents of the juice to sugar $[6,9]$.

The refractive index of the samples at $20^{\circ} \mathrm{C}$ was considerably close to each other with BL1 and BL2 having the same value of 1.342 while BL3, BL4 and BL5 have 1.344, 1.346 and 1.345 respectively. These values are similar to those reported for orange, grape and tomato juices by Tressler [11].

The total sugar (\%) of 0.60 for SPJ was more than twice the amount found in SWJ (4.25). The amount of total sugar in the two standards and all the blends were lower than $18.10 \%$ and $18.28 \%$ obtained for both the improved and indigenous juice from Jamun fruit [3].

The result revealed that addition of pineapple juice to the watermelon juice led to increase in the sugar content while reversing the process reduced the sugar content of blends. The total sugar content of some of the blends fell within the value of $9.9 \%$ and $11.1 \%$ reported for grape and orange juices respectively by Gergen, [12].

The sucrose content in $\%$ was higher in the standard pineapple juice $(10.00 \%)$ than the watermelon juice $(4.00 \%)$. Sucrose is one of the disaccharide that is very useful to the body in the provision of energy.

The percentage ash content of the watermelon juice was found to be more than that of pineapple juice. Ash content is a very good index of the mineral contents of a sample and therefore the standard juice samples and the various blends could serve as good and very cheap source of nutritive mineral elements to the body.

The moisture content of SWJ of $92.50 \%$ was higher than $83.55 \%$ obtained for SPJ. The moisture content of the blends decreases with increase in the proportion of watermelon in the blends.

The organic matter (\%), specific gravity, temperature, conductivity and viscosity properties of the fruit blends followed the same pattern as observed for $\mathrm{pH}$, total sugar and sucrose contents.

\section{Conclusion}

The present study showed that blending of fruit juices could enhance their nutritional quality and development of new products. The information therein will assist in providing knowledge base evaluation and development of blends that may benefit fruit processing industry in Nigeria.

\section{References}

[1] C. Costescu, D. Parvu and A. Rivis, The Determination of some Physical-Chemical Characteristics for orange, Grapefruit and Tomato Juices. Journal of Agroalimentary Processes and Technologoes Vol. XII No 2 (2006):429-432.

[2] P.T. Rapisarada, L.C. Anthonio and A. Rosella, Antioxidant Effectiveness as Influenced by Phenolic Content of Fresh Orange Juice. J. Agric. \& Food Chem. 47 (1999):4718-4723.

[3] M. Shahnawaz and S.A. Shiekh, Analysis of Viscosity of Jamun Fruit Juice, Squash and Jam at Different Compositions to Ensure the Suitability of Processing Applications. International Journal of Plant Physiology and Biochemistry. Vol. 3(5) (2011):89-94.

[4] M.D. Aleem-Zakir, T.R. Genitha and I.H. Sijed, Effects of Defatted Soy Flour Incorporation on Physical, sensorial and Nutritional Properties of Biscuits. Journal of Food Processing and Technology. 3 (2012):1-4.

[5] T.O. Akinwale, Cashew Apple Juice: Its use in Fortifying the Nutritional Quality of some Tropical Fruits. Eur. Food Res Technol. 211(2000):205-207.

[6] A.H. Borghani, R. Abdul and I.H. Syed, Development and storage of Blended Papaya-Aloe Vera Ready to Serve (RTS) Beverages. J. Food Process \& Technol. Vol. 3, Issue 10 (2012):1-4.

[7] U. Ravi, L. Menon, M. Aruna and B.K. Jananni, Development of Orange-white Pumpkin Crush and Analysis of its Physicochemical, Nutritional and Sensory Properties. American-Eurasian j. Agric. \& Environ. Sci. 8(1) (2010):44-49.

[8] A.M. Zatylny, W.D. Ziehl and R.G. St-Pierre, Physicochemical Properties of Fruit of Chokecherry (Prunus virginiana L.), Highbush Cranberry (Viburnum trilobum marsh.) and Black Currant (Ribes nigrum L.) Cultivars grown in Saskatchewan. Canadian Journal of Plant Science. (2004):425-429.

[9] M.S. Jakhar and S. Pathak, Studies on the Preparation and Storage of Blended Ready-to-serve from Ber (Zizyphus mauritiana lamk.) and Jamun (Syzigium cuminii Skeels) Pulp. Plant Archives. 12 (2012):533-536.

[10] A. Mustafa Ozgen, C. Durgac, S. Sedat and C. Kaya, Chemical and Antioxidant Properties of Pomegranate Cultivars of Pomegranate Cultivars grown in the Mediterranean Region of Turkey. Food Chemistry. 111(3) (2008):703-706.

[11] D.K. Tresler and M. Joslyn, The Chemistry and Technology of Fruit and Vegetable Juice Production, (1971), New York, AVI Publishing Co.

[12] I. Gergen, Analiza Produselor agroalimentare-Principii, Metode, Applicatii, Editura Eurostampa, Timisoara (2004). 